\title{
Identifying the Reasons Why Companies Abandon Collaborative Networks
}

\author{
Rolando Vargas Vallejos, Paulo Fernando Pinto Barcellos, \\ Margareth Rodrigues de Carvalho Borella, and Rosimeri Machado \\ University of Caxias do Sul, PPGA, Francisco Getúlio Vargas 1130, 95070-560, \\ Caxias do Sul, RS, Brazil \\ \{rvvallej, pfpbarce, mrcborel\} @ucs.br, \\ \{rosimeri.machado\} @ponzoni.com.br
}

\begin{abstract}
The present work identified possible factors that led some collaborative network organizations to close. The case study was based on experiences obtained in networks that took part of the Collaborative Network Program of the State of Rio Grande do Sul (Brazil). One of the Program creators, managers, consultants and entrepreneurs of six networks that broke down were interviewed based on a semi-structured instrument. The analysis of the Collaborative Network method indicated that important factors could motivate the failure of networks, which were validated with the integrated model of alliance failure proposed by Park and Ungson [1]. The article ends by suggesting some improvements in the Collaborative Network Program of the State of Rio Grande do Sul to become more efficient and contribute to the network success.
\end{abstract}

Keywords: Collaborative Network Organization, Collaborative Network Method, Network Failure.

\section{Introduction}

The collaborative network model of cooperating to compete started with the studies of Brandenburger and Stuart [2] and Brandenburger and Nalebuff [3] who popularized the term "coopetition" [4]. Porter [5] who has systemized competition strategies of individual companies, also considers the strategy of cooperation as an alternative to compete and develop a competitive advantage.

There are several studies of Collaborative Networks Organizations (CNOs) success in the State of Rio Grande do Sul [6] and [7], among others. However, few studies describe the failures of Collaborative Networks. For this reason, this paper aims at contributing to the development and/or improvement of methods and practices to be used for the success of future Collaborative Networks.

The Collaborative Network Program of the State of Rio Grande do Sul (CNPRS) is an initiative of the Government in order to stimulate small and medium enterprises to become more competitive. The Program begun in 2000 and, therefore, it is important to identify the reasons why companies, which integrate collaborative networks, 
abandon them. This identification may help to create new successful CNOs, and especially to support the existing ones. The research question therefore is: which are the reasons why enterprises that belong to CNPRS give it up?

\section{Failures in Collaborative Network Organizations: Theoretical Background}

In the last two decades, a special attention has been paid to CNOs, which are formed by several entities (e.g., organizations and specialists) that are autonomous, geographically distributed, and heterogeneous in terms of their operating environment, culture, social capital, and goals. These entities collaborate with each other to achieve common goals, and their interactions are supported by Information and Communication Technology (ICT) [8]. Under an economic perspective, a network organization may be an answer to the competitive pressure over individual enterprises to increase their competitiveness in production, new products development and launching, new technologies access, and knowledge share among suppliers, customers and competitors [9].

A large number of research projects involving CNOs are carried out worldwide, and a growing number of practical cases have been reported. Camarinha-Matos and Afsarmanesh [10] have raised the need for modeling to understand, manage, simulate, and predict the behavior of CNOs.

The concept of breeding environment has emerged as the necessary context to support the effective creation of CNOs. Shortly, Virtual organization Breeding Environment (VBE) is an association of organizations and their related supporting institutions, adhering to a long-term cooperation agreement, and adopting common operating principles and infrastructure. The target of this association is the preparation of its members and the increase of their chances to collaborate in potential Virtual Organizations [11].

All of these aspects have been discussed by studies that approach CNOs success. This study, however, refers to causes that lead to unsuccessful CNOs. According to the Park and Ungson Model [1], problems with trust, reputation and commitment among network members undermine the network desired objectives such as equity, efficiency and adaptation, leading to failure (Figure 1).

Others factors have been reported as contributors to the network failure:

- the growing number of members that increases the conflict risk, disrupting the CNO [12];

- CNO institutional consolidation problems leading to cognitive, social and political blocking, as well as attitudes that do not generate new benefits to the network members [13];

- no achievement of common objectives centered on knowledge acquisition, learning, cost reduction, gains of scale, adaptation to change, risk decreasing, assets integration, and training [14]. 


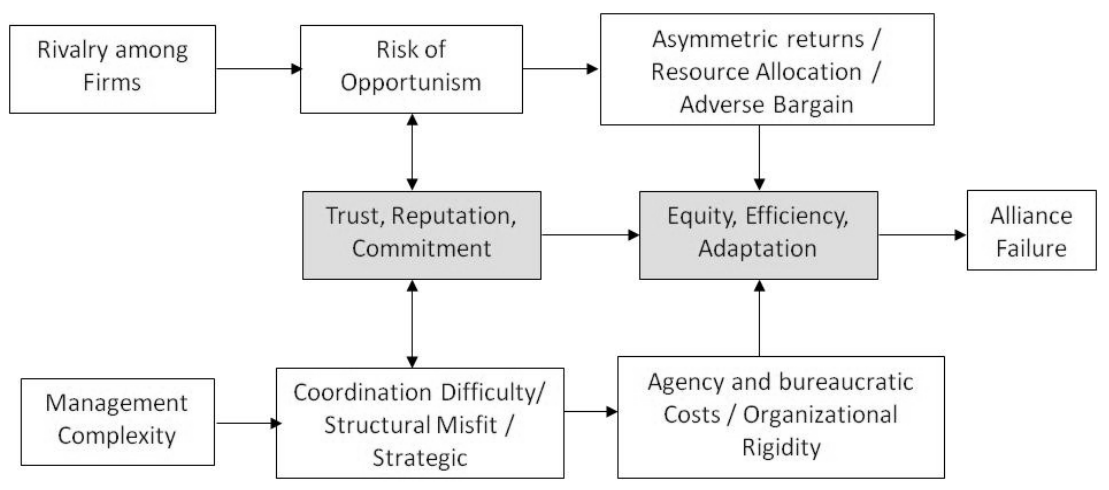

Fig. 1. An Integrated model of Alliance Failure

\section{Collaborative Networks in the State of Rio Grande do Sul}

The State of Rio Grande do Sul, the southernmost state in Brazil, bordering with Argentina and Uruguay, seeking to incorporate the development of small and medium size enterprises as an alternative to foster the state's economy, is encouraging the building of organizational networks since the year 2000 .

The State, through the Development and International Affairs Department (SEDAI), established a Collaborative Network Program, emphasizing the associative culture among small businesses that operate in various segments such as industry, commerce, service, agribusiness, and, recently, the third sector. The program aims at "... promoting the formation of collaborative networks joining business strategies, mutual cooperation between enterprises and institutions in order to establish integration among the State and the various sectors of the society" [15].

The effective operation of the program is based on a specific method developed by SEDAI, which is transferred to universities. The universities are the partner institutions that hold the knowledge about the peculiarities of each region and play the role of liaison between the public and private sector. The university has a program coordinator and is responsible for the selection of consultants who are qualified according to the program method. These consultants are responsible for identifying networking opportunities, diagnosing the existence of common ground among business, and assisting in actions planning to build collaborative networks.

The working method is the same for any sector, and the developed networks under this design process present the same organization strategy and tools. The steps shown in Figure 2 form the SEDAI Collaborative Network method [15].

Networks formed by the Collaborative Network method are structured to allow CNO members to participate in the network activities through the board, councils, and working committees. CNO governance responsibilities are split as follows:

General Members Meeting. It is the forum where proposals that involve the interests of the network are approved or disapproved. The process is democratic, where every member has one vote, regardless of the company size. According to the established 
rules, each network requires a minimum quorum of participants to validate the decisions.

Board. Responsible for developing the statute, the code of ethics, operational procedures, and legal rules to represent the network interests. The board is elected by majority vote. Each network defines the succession process in accordance with its legal rules.

Councils. Play the role of assisting the board in order to reach network interests, and are usually formed by boards of directors, ethics and taxation. Councils are also elected by majority vote.

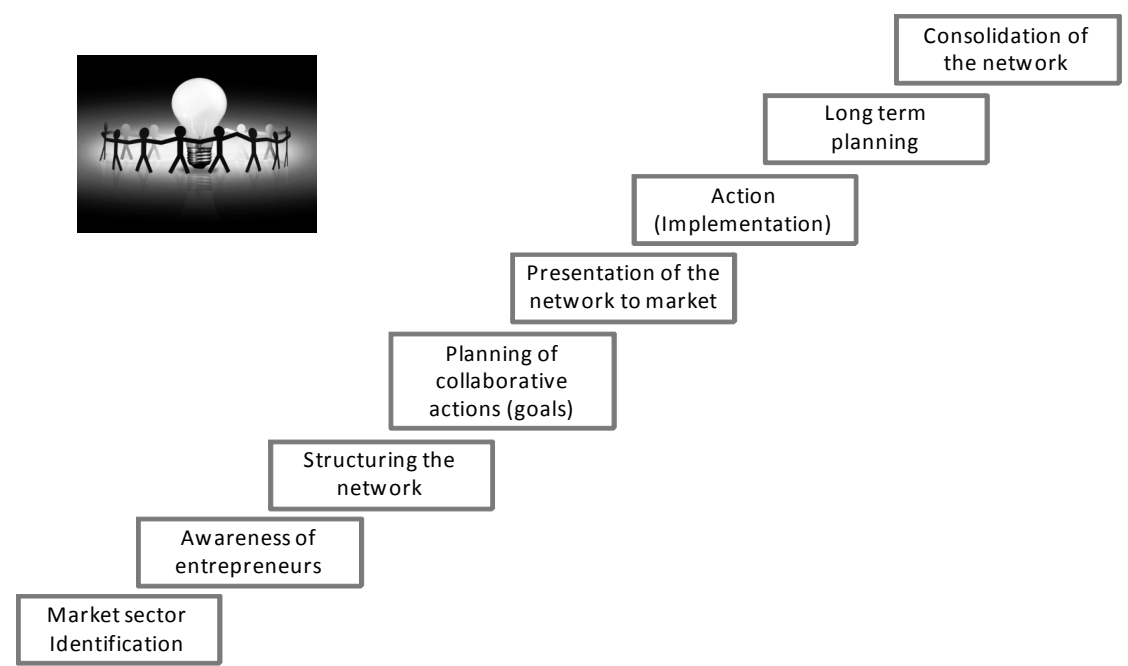

Fig. 2. The SEDAI Collaborative Network Method

Manager/Executive. (Only present in some networks) is usually a professional hired by the network to fulfil the role of reconciling members' interests, in order to implement strategies approved by general members meetings, as well as to deal with the network routines.

Staff. Operational issues related to the network running.

Coordinators. Members are responsible for strategic committees, which play an active role. The Coordinator appointment is due to member's leadership and to his identification with the area of each committee activity.

Strategic Committees. Are formed by members whose roles in the committee must fit their profiles. Strategic committees are the base of collaborative networks operation and performance in accordance with the SEDAI Collaborative Networks method. In general, committees are divided into four activity areas: Marketing, Innovation, Expansion and Negotiation. Committees have autonomy to develop proposals of activities to be implemented by the CNO. The general members meeting is the adequate forum where such propositions are approved. 


\section{The Research Method}

This is a descriptive study based on multiple cases, where one of the program creators and managers, one senior consultant and one program coordinator of the CNPRS were interviewed, also twelve entrepreneurs of six collaborative networks located in the region of Caxias do Sul, which became extinct, were interviewed. These collaborative networks were constituted through the SEDAI Collaborative Network method. The University of Caxias do Sul (UCS) was the Program partner university.

The first phase of this study involves the analysis of the senior consultant' interview, showing the relevant and probable causes that contributed to the failure of these networks, validated with the UCS Program coordinator and one of the program creators and managers. In the second phase, those factors that contributed to the networks failure were identified from the content analysis of semi-structured interviews with twelve entrepreneurs. The respondents were the companies' owners, former members of six collaborative networks. Two companies were interviewed in each of the studied networks (Furniture, Wine and Grape, Non-Governmental Organizations, Footwear, Glazing and Electronic Security Equipment sectors).

The Collaborative Network method was analyzed, and important factors that could motivate the failure of those networks were identified. Finally, those identified factors were validated with the integrated model of alliance failure proposed by Park \& Ungson [1].

\section{Identifying the Failures Factors of Rio Grande do Sul CNO's}

Factors blamed for CNOs failure in the state of Rio Grande do Sul can be divided into two groups according to: (1) consultants' point of view, and (2) entrepreneurs' point of view.

\subsection{Consultant's Point of View}

The analysis of the consultants' interviews has identified factors that may explain the reason for some failures occurred within CNPRS. These factors were validated with the UCS Program coordinator and one of the program creators and managers of the CNPRS, and can be classified in two main groups, one inside and the other outside the CNO. Factors are presented in Figure 3.

Inside CNO Factors. There are specific characteristics of the CNO that have proven to be relevant for the failure or success of the network itself. Among them, the following factors can be mentioned:

The CNO president's profile. Entrepreneurs should be trained to develop leadership and conflict management. They must be trained to develop better network governance. 
Attitudes and behaviors as an outcome of participants' mind models. When there is a concentration of less flexible participants in the group their attitudes and behaviors tend to a radical positioning, and a group mind model is difficult to be built.

Trust among CNO participants. This is a mandatory factor to explain CNOs failure. Trust absence is a barrier to a joint work of the participants as a sole entity.

The need for several professionals in the CNO. The lack of professionals in the CNO can erode trust among participants leading to an inadequate internal environment, which will end up by the network organization failure.

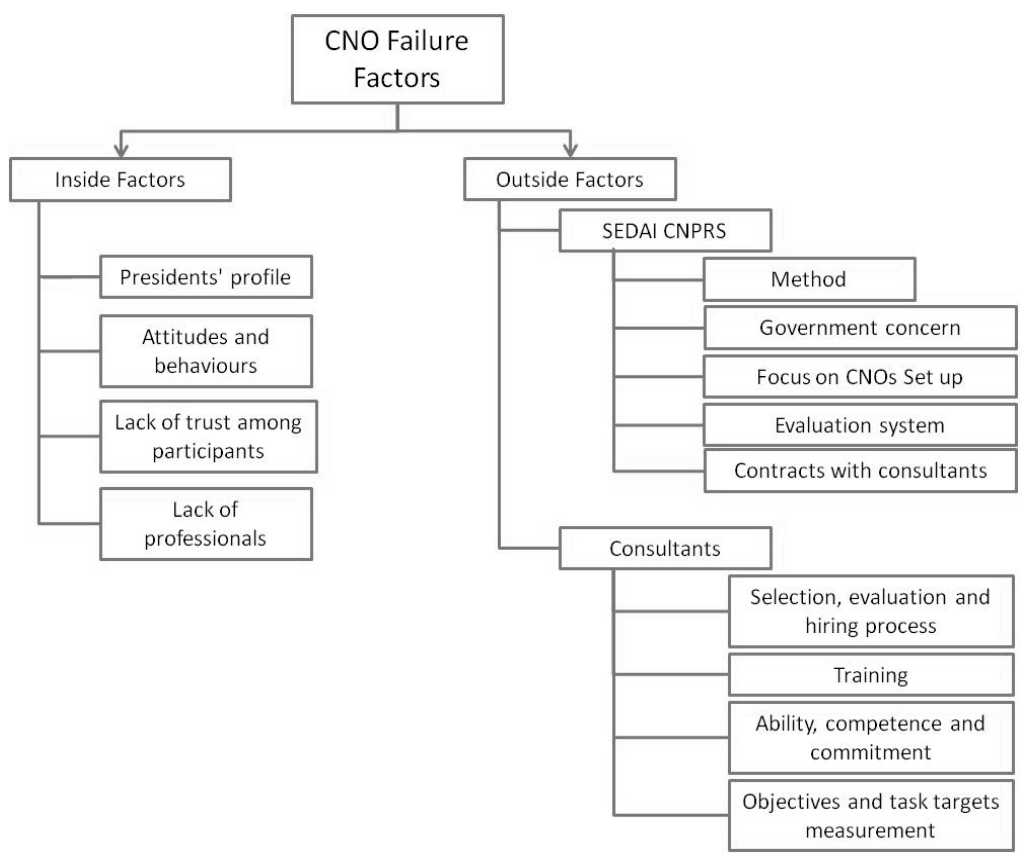

Fig. 3. Failure factors according to CNPRS consultants

Outside CNO Factors. These are factors found outside the network organization. Among important factors the following ones can be considered:

The method adopted by SEDAI. The SEDAI Collaborative Networks method is a robust one. However, some points call for attention according to the experience acquired along time by the consultants from the University of Caxias do Sul involved in CNOs support. Some of these concerns are referred in the following items.

Government concern with CNPRS. From the Government side, the CNPRS is not sustainable since the financial support from the Government to the program is subject to break offs, generating troubles to partner universities which have to maintain an operational structure to keep the project running. 
CNPRS consultants' selection, evaluation, and hiring process. In the beginning of the CNPRS, the consultant selection process was based on interviews with several people such as the university extension program director, the CNPRS coordinator, and a psychologist. However, that process has changed along the years. Right now, it is not a rigorous process anymore.

CNPRS consultants training. There was a well-structured training program for the consultants but its duration time was being reduced gradually. Nowadays, that procedure is just past.

CNPRS consultants' ability, competence, and commitment. The consultant role is basic for the network organization start up and initial footsteps. The development of adequate attitudes and behavior by consultants is required for their commitment to the program. The consultant works in the CNPRS forefront. Thus, the personal factor is relevant for the consultant development but it is not considered by the SEDAI method.

CNPRS consultants' main objectives and task targets measurement. Usually consultants are measured by the quantity of CNOs, which are created without any concern with the quality of the resulting network organizations.

Type and duration time of the CNPRS contract with consultants. Another aspect to negatively impact on consultants' motivation is the type of the contract they are submitted to, under a clause of limited duration, and an explicit expiration date.

CNPRS focus on CNOs set up. The SEDAI method does not foresee the network organization follow up by consultants; the focus is on the CNO set up.

CNPRS evaluation system. The CNPRS evaluation is done through an executive summary made by the program supervision - the partner university - that is sent to SEDAI. The success factor is not considered.

\subsection{Entrepreneur's Point of View}

Empirical results of twelve interviewed entrepreneurs of six extinct collaborative networks located in the region of Caxias do Sul are represented in Figure 4. These aspects can be considered as possible variables to drive the decision of abandoning their networks.

Based on the content analysis, the conclusion that the entrepreneurs' decision of abandoning the collaborative network is related with the particular culture of each network member, according to his own way to conduct his business, was reached to. Structural aspects are important in providing network sustainability; however, structural discrepancies among network members make it difficult to establish a common culture in the collaborative network.

Some respondents' comments show the coexistence of individual and network iteration causes that could have influenced the decision to leave their networks, as shown below: 
"... one was leaving after the other...", "... there were complaints about the travel time for the meetings ..."," ... some members were participating only to learn how other companies were working and did not share anything ...", "... when only three companies remained in the $\mathrm{CNO}$, we decided to close the network, finally ..." (Respondent of the Furniture Industry Network).

"...I was the youngest member of the network, the others were older than me and they had more experience with the grape business ...", "... everyone distrusted of what I said ...", "... they thought that my ideas were too modern ...","... with the members' lack of trust, I decided to leave the network ..." (Respondent of the Wine and Grape Industry Network).

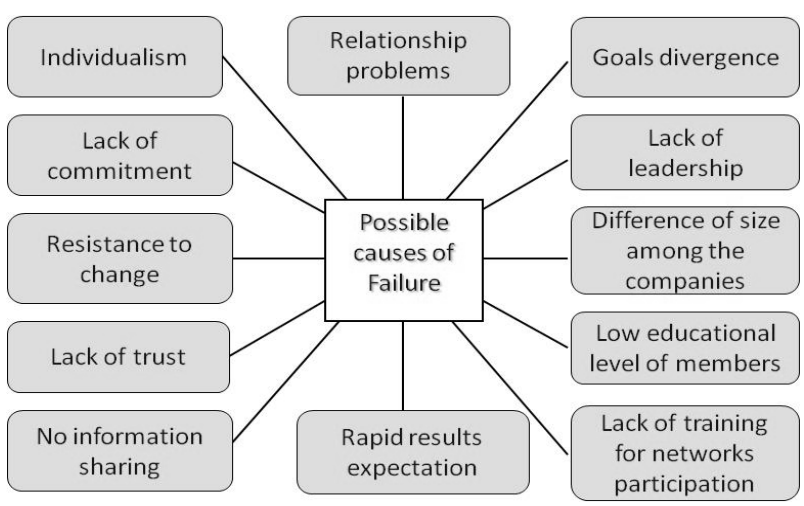

Fig. 4. Reasons for abandoning CNOs according to Entrepreneurs

\section{Conclusions}

The analysis of the interviews with one of the CNPRS creators and managers, consultants and entrepreneurs indicate that CNOs that are being developed in industrial districts have some advantage - as, for instance, a common business culture and a sense of community - when compared to networked organizations that are geographically spread. It is a belief that despite being geographically concentrated in a same place CNOs should be prior prepared to form alliances.

Considering the Park and Ungson Model, it is possible to say that the research shows the "rivalry among firms" and the "management complexity". It was detected from the interviews that those firms that fail to consolidate the CNO do not build trust, reputation, and commitment. For that reason, equity, efficiency and adaptation cannot be developed. To minimize this situation for the future, in the particular case of SEDAI Collaborative Network method, improvements are suggested, having in mind some method phases and activities.

In the present work, CNOs' inside and outside possible failure factors are differentiated. Among the internal factors, a lack of structure and preparation to allow network participants better prepare for developing trust, attitudes and the necessary behaviors to collaborate were detected. Even though, in the Collaborative Network 
method the following steps are considered: (1) network structuring, (2) long term planning (that is questioned by the consultants), and (3) network consolidation. These steps should be strengthened because the interviewed entrepreneurs have raised questions like: lack of commitment, individualism, resistance to change, lack of trust, no information sharing, and relationship problems. Other important inside CNO factor is the qualification of the $\mathrm{CNO}$ president and its professionals, pointed out by the consultants as preparedness of the president and lack of professionals, and by the entrepreneurs as lack of leadership and low educational level of CNO members. Furthermore, entrepreneurs should be trained to develop leadership and conflict management. Some of them will be a CNO president in the future. Network success depends on entrepreneurs' commitment and management ability. Thus, they must be trained to develop the best network governance. Therefore, the creation of a new step in the SEDAI Collaborative Network method is suggested: qualification and preparation of CNOs presidents.

Considering the outside CNO factors, other contribution of the present work is the identification of the need for investing in the preparation and qualification of the CNPRS' consultants. In the beginning, the CNPRS Program included a structured consultants training but its duration time was increasingly reduced. Furthermore, the consultant qualification must be considered as one of the criteria for selection, evaluation and hiring processes. Thus, the creation of a new step in the SEDAI Collaborative Network method is suggested: qualification and training of consultants. From the Government side, the CNPRS needs to be supported constantly. The effectiveness of the CNPRS method will assure the future success of the network.

Acknowledgments. The University of Caxias do Sul is supporting this work.

\section{References}

1. Park, S.H.E., Ungson, G.R.: Interfirm Rivalry and Managerial Complexity: A Conceptual Framework of Alliance Failure. Organization Science 12(1), 37-53 (2001)

2. Brandenburger, A.M.E., Stuart Jr., H.W.: Value-based Business strategy. Journal of Economics and Management Strategy 5(1), 5-24 (1996)

3. Brandenburger, A.M.E., Nalebuff, B.J.: Coopetition. Doubleday, New York (1996)

4. Rodrigues, L.C., Maccari, E.A.E., Riscarolli, V.: Structure and cooptation in organization network. Journal of Information Systems and Technology Management 4(2) (2007)

5. Porter, M.E.: On Competition. The Harvard Business Review Book Series (1998)

6. Vallejos, R.V., Lima, C., Varvakis, G.: A framework to create a virtual organisation breeding environment for small and medium enterprises. International Journal of Services and Operations Management 6, 335-351 (2010)

7. Barcellos, P.F.P., Galelli, A., Mueller, A., Reis, Z.C., Peretti, J.L.G.: Collaborative Networks: an innovative approach to enhance competitiveness of small firms in Brazil. In: Thoben, K.D., Pawar, K.S., Gonçalves, R. (eds.) Proceedings of the 14th International Conference on Concurrent Enterprising, ICE 2008, pp. 211-216 (2008)

8. Camarinha-Matos, L.M., Afsarmanesh, H.: Collaborative Networks: A new scientific discipline. Journal of Intelligent Manufacturing 16, 439-452 (2005) 
9. Balestrin, A., Vargas, L.M., Fayard, P.: Criação de Conhecimento nas Redes de Cooperação Interorganizacional. Revista de Administração de Empresas 45(3), 52-64 (2005)

10. Camarinha-Matos, L.M., Afsarmanesh, H.: A framework for virtual organization creation in a breeding environment. Annual Reviews in Control 1(31), 119-135 (2007)

11. Castells, M.: A era da informação: economia, sociedade e cultura. Paz e Terra, São Paulo (1998)

12. Messner, D., Meyer-Stamer, J.: Governance and networks. In: Oliver, A., Ebers, M. (eds.) Networking Network Studies: an Analysis of Conceptual Configurations in the Study of Interorganizational Relationships. Organization Studies, vol. 19(4), pp. 549-583 (1998)

13. Pereira, B.A.D., Venturini, J.C., Wegner, D., Braga, A.L.: Desistência da Cooperação e Encerramento de Redes Interorganizacionais: em que momento essas abordagens se encontram? Revista de Administração e Inovação 7(1), 62-83 (2010)

14. Ebers, M.: Explaining interorganizational network forming. In: Ebers (ed.) The Formation of Inter-Organization Networks, Oxford (1997)

15. Secretaria do Desenvolvimento e Assuntos Internacionais do Rio Grande do Sul - SEDAI: Manual de Orientação dos Consultores do Programa Redes de Cooperação. Porto Alegre, RS, Brazil (2004) 